\title{
The Second Class of Applied Undergraduate Mathematics and the Practice of College Students' Innovative Ability Cultivation
}

\author{
Peiyu Yan \\ Basic Teaching Department \\ Shandong Huayu University of Technology \\ Dezhou, Shandong, China 253034 \\ yan1982fang@163.com
}

\begin{abstract}
With the goal of cultivating the innovative ability of college students, this paper constructs the second classroom activity model of "three combinations and three progressions" , and continuously enriches the content of activities to maximize the students' innovative ability. At the same time, the evaluation system of college students' innovation ability based on the second classroom activity of mathematics is constructed. The fuzzy comprehensive evaluation based on the analytic hierarchy process is used to comprehensively evaluate students' innovation ability. It is concluded that the second classroom activity of mathematics has a positive effect on the cultivation of college students' innovative ability.
\end{abstract}

Keywords-creativity; mathematics second class; innovation ability evaluation system; fuzzy comprehensive evaluation

\section{INTRODUCTION}

At the Summer Davos Forum in September 2014, Comrade Li Keqiang put forward the policy orientation of "mass entrepreneurship and innovation". These related policies put forward higher requirements for the cultivation of contemporary college students' comprehensive quality and entrepreneurial spirit. The innovative ability of college students should have basic knowledge, professional knowledge, instrumental knowledge or methodological knowledge as well as teamwork spirit, social communication ability, and comprehensive knowledge application ability [1]. The innovation ability training system of college students is composed of classroom teaching and extracurricular teaching. Carrying out a variety of mathematics second classroom activities can not only promote students' timely "digestion" of mathematics first classroom knowledge, strengthen the monitoring of students' post-learning effects, but also build a platform for students to express themselves and create a rich learning atmosphere. Meanwhile, it also can help students to find problems, expand knowledge areas, cultivate the innovative spirit and improve innovation capabilities.

\section{MATHEMATICAL SECOND CLASSROOM ACTIVITY BASED ON THE CULTIVATION OF COLLEGE STUDENTS' INNOVATIVE ABILITY}

A. The activity pattern of "three combinations and three progressions" in the second mathematics classroom

The three combinations are the combination of personal hobbies and mathematical and cultural content, the combination of the second classroom training of mathematics and the content items of the first classroom of mathematics, and the combination of the content of mathematics second classroom exercises and the social hot issues.

The three progressions are the second classroom activity of mathematics. That is divided into interest layer, knowledge layer and capability layer. Because each student's preference for mathematics is different, it is impossible to require all students to participate in the second class of mathematics activities. So three levels of activities are tailored for students to choose according to their personal preferences. First of all, through mathematics culture and mathematics in life, students can recognize the charm of mathematics and the role of mathematics, gradually stimulate students' interest in learning, and maximize the participation of most students in the activities of interest. It also lets students understanding the beauty and the usefulness of mathematics through the visual, hearing, and feeling. Secondly, cultivate some students who are more interested in mathematics and are willing to acquire more knowledge to participate in the activities of the knowledge level. Through extracurricular training and after-school instruction, these students can gradually improve the basic knowledge of students. The teacher can encourage this part of the students to participate in math competitions above the school level. Finally, for some students with solid foundations in mathematics and strong practical application skills, the individuality potential of these students, their innovative spirit and innovative ability are gradually cultivated through carrying out activities for the expansion level. 


\section{B. Enrich the content of the second class of mathematics} Activities

\section{1) Conducting a series of lectures on mathematics}

Mathematics is not only an important basic course but also a very important culture. In order to gradually infiltrate the mathematics culture into the students' thinking, let the students truly feel the beauty of mathematics and the value of mathematics, stimulate students' sense of innovation and awaken the creativity of students, the group organized lectures and salons with the theme of "How to Learn Mathematics", "Understanding Mathematical Modeling", "Mathematical Celebrity Forum", and "Interesting Mathematics". Through some interesting and thoughtprovoking questions, combined with the actual life of students, the culture is shown from the history of the development of mathematics, the dialectical thinking of mathematics, the practical application of mathematics, the symbolic language of mathematics, etc. Mathematics allows students to realize that mathematics is not only a useful tool in life, but also knowledge of the calculus that is learned in the classroom. Mathematics is like a vast ocean that can be extended to all aspects of social life. When students really understand the value of mathematics, I believe that in the future students, they will not only see boring mathematics, they will gradually like mathematics.

2) Organize students to participate in various skill competitions at all levels

Organize students to participate in various skill competitions, reform activities, enrich the content of activities and cultivate students' mathematics application ability and independent innovation ability. On the one hand, we should break the competitions that were organized in the form of "exams" in the past, use "a paper" to judge students' mastery of mathematics knowledge and cultivate the students' innovative ability. On the other hand, the enriching of competition's types should be focused on.

\section{3) Opening mathematics related elective courses}

Enrich the content of mathematics electives. In order to further develop the students' vision, cultivate students' ability in hands-on operation, logical thinking, knowledge acquisition, unity and cooperation, and gradually improve the comprehensive application level of students, we should produce the exquisite teaching courseware, guide students to learn to observe, to make conjectures. Meanwhile, let the students feel the magic of mathematics more intuitively through mathematical software, gradually form the conscious operation when thinking about problems, to explore the essence of the problem and gradually improve the students' creative thinking.

\section{4) Forming a Math Society}

With the participation in the second classroom activity of mathematics, more and more students want to understand mathematics, love mathematics, and are willing to put forward suggestions for mathematics activities and make arrangements. Therefore, mathematics society for students is established. It provides students with another communication platform, and also lays the foundation for the selection of innovative talents and connotation construction.

\section{NEW ENERgy CHARgING StATION AND GRID POWER EXCHANGE}

The undergraduate course of "Advanced Mathematics" is guided by the application of ability training, and promotes the "three combinations" of the teaching content of the "Advanced Mathematics" course; the case teaching method is the "one main line" to promote the study of the teaching method of the "Advanced Mathematics" undergraduate; With the goal of quality, we will promote the "diversification" of the curriculum evaluation method; and finally realize the "two improvement" of students' mathematical literacy and application ability.

Introduce the content of the second math class to the first class. For example, the introduction of mathematics culture, mathematical modeling cases, mathematics competition questions, and mathematics common sense into the classroom can stimulate students' interest in learning mathematics and mobilize the enthusiasm and initiative of learning. On the other hand, change students' "indigestion" phenomenon. let students gradually form a "why learn - learn what - how to learn - how to use" learning mode, so that students solid "martial arts foundation", and for research and development new The "martial arts move" laid the foundation.

First of all, according to the application-oriented undergraduate professional needs reform mathematics curriculum syllabus (such as higher mathematics, probability theory and mathematical statistics, etc.), optimize the teaching content. Based on the purpose of solving practical problems, the focus of teaching is on the cultivation of students' mathematics application ability.

Secondly, collect teaching cases of various mathematics courses, organize, screen, unify requirements, systematically plan, compile relevant teaching case sets and after-school review materials, and integrate them into instructional design according to the characteristics of the students they teach, so that teachers will Teaching cases run through the actual teaching of the classroom.

Finally, establish a diversified assessment and evaluation method to strengthen the intensity of teaching process assessment.

\section{RESEARCH ON THE EVAluation SyStem OF College STUDENTS' INNOVATION ABILITY BASED ON THE SECOND CLASSROOM ACTIVITY OF MATHEMATICS}

Some developed countries in Europe and America attach great importance to the implementation of the second classroom activities, emphasizing the cultivation of students' innovative ability and professional ability, emphasizing the construction of campus culture [2], and foreign countries have more extensive research on the factors of evaluating innovation ability [3]. Therefore, based on the theory of multiple intelligences, this paper takes the second classroom activity of mathematics as the carrier and adopts the fuzzy comprehensive evaluation method based on the analytic hierarchy process. In the process of research, explore the activity content of the second classroom 
from mathematics, the first classroom The assessment method and the student evaluation system combines the three aspects of theory and practice and the two-way improvement of the students' "hardware" and "software", that is, the professional application ability of the students is improved under the improvement of basic knowledge and application level. Based on the spirit of innovation and collaboration, students' entrepreneurial and employability has also improved. Therefore, the evaluation system of college students' innovation ability based on the combination of theory and practice of mathematics second classroom activities is established.

\section{A. Structure diagram of college students' innovation ability evaluation system based on the second classroom activity of mathematics}

In order to improve the evaluation system of college students' mathematics courses in applied undergraduate colleges, cultivate students' innovative consciousness, enhance students' practical application ability, develop students' mathematical literacy and scientific spirit, and promote the overall improvement and individualized development of students' comprehensive quality [4]. The innovation ability of college students is divided into four parts: the ability to acquire knowledge, the ability of agile thinking, the ability of flexible practical application and the ability of extensive social communication. And the development of targeted mathematics second classroom activities, the construction of the evaluation system of college students' innovative ability.

TABLE I. EVALUATION ARCHITECTURE DIAGRAM

\begin{tabular}{|c|c|c|}
\hline \multirow{14}{*}{ 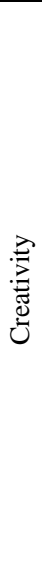 } & \multirow{4}{*}{ Access to knowledge } & Lecture \\
\hline & & On-campus mathematics competition training \\
\hline & & On-campus mathematical modeling training \\
\hline & & National College Student Mathematics Competition \\
\hline & \multirow{4}{*}{ logical thinking ability } & Fun Magic Cube Math Competition \\
\hline & & On-campus Sudoku competition \\
\hline & & Game theory elective course \\
\hline & & In-school mathematics knowledge contest \\
\hline & \multirow{4}{*}{ Practical application ability } & National College Students Mathematical Modeling \\
\hline & & Statistical survey or modeling paper \\
\hline & & Access to relevant literature \\
\hline & & Mathematical experiment office software elective \\
\hline & \multirow{2}{*}{ Social communication ability } & attending community activities \\
\hline & & Social questionnaire \\
\hline
\end{tabular}

B. Determination of the weight of evaluation indicators based on the analytic hierarchy process

In the judgment, the importance of each evaluation index factor is different. This paper applies the analytic hierarchy process to calculate the weight of each level of evaluation indicators.

Index weights of primary indicator factors. First, determine the judgment matrix[5]:

$$
\left[\begin{array}{cccc}
1 & 2 & 1 & 2 \\
\frac{1}{2} & 1 & \frac{1}{2} & 1 \\
1 & 2 & 1 & 2 \\
\frac{1}{2} & 1 & \frac{1}{2} & 1
\end{array}\right]
$$

The maximum eigenvalue calculated by MATLAB software is $\lambda_{\max }=4$. The consistency index calculated by the formula is $C I=\frac{\lambda_{\max }-n}{n-1}=0$, The random consistency index is $R I=0.90$ by looking up the table[6]. The consistency ratio indicator is $C R=\frac{C I}{R I}=0<0.10$. Then, the consistency of the judgment matrix can be considered to be acceptable, so that the weights of each factor are calculated by the feature root method:

$$
A=(0.46,0.23,0.155,0.155)
$$

The second-level indicator weight vector is equally available.

$$
\begin{gathered}
A_{1}=(0.75,0.25) A_{2}=(0.18,0.36,0.36,0.1) \\
A_{3}=(0.33,0.17,0.33,0.17) \\
A_{4}=(0.43,0.21,0.21,0.15)
\end{gathered}
$$

\section{Determination of fuzzy comprehensive evaluation matrix}

More than 2,000 students participating in the second class of mathematics activities were divided into mild participants, moderate participants, and deep participants according to their participation activities [7], and three students were randomly selected from them.

According to the situation of their participation in the activities, one student (Liu Yu) was randomly selected as the evaluation object among the students who participated in the second class of mathematics activities. The 10 teachers who 
participated in the organization and training guidance of the second class of mathematics were experts. In the group, the evaluation indicators of the student's participation in the activity and its performance are scored. The evaluation matrix is:

$$
\begin{aligned}
R_{12} & =\left[\begin{array}{lllll}
0 & 0.4 & 0.4 & 0.2 & 0 \\
0 & 0.2 & 0.5 & 0.3 & 0 \\
0 & 0.2 & 0.5 & 0.3 & 0 \\
0.3 & 0.5 & 0.2 & 0 & 0
\end{array}\right] \\
R_{13} & =\left[\begin{array}{lllll}
0 & 0 & 0 & 0 & 1 \\
0.2 & 0.3 & 0.5 & 0 & 0 \\
0.2 & 0.4 & 0.4 & 0 & 0 \\
0.2 & 0.4 & 0.3 & 0.1 & 0
\end{array}\right] \\
R_{14} & =\left[\begin{array}{lllll}
0.1 & 0.2 & 0.5 & 0.2 & 0 \\
0.1 & 0.4 & 0.5 & 0 & 0
\end{array}\right] \\
R_{11} & =\left[\begin{array}{lllll}
0.2 & 0.5 & 0.3 & 0 & 0 \\
0 & 0.5 & 0.5 & 0 & 0 \\
0 & 0.6 & 0.2 & 0.2 & 0 \\
0 & 0.3 & 0.3 & 0.4 & 0
\end{array}\right]
\end{aligned}
$$

According to the evaluation results, the Zadeh operator is used. Combine the $\mathrm{A}$ and $\mathrm{B}$ evaluation matrices to obtain a comprehensive evaluation vector $B=A \circ R$, The resulting comprehensive judgment matrix for students' ability to innovate is:

$$
R=\left[\begin{array}{lllll}
0.25 & 0.25 & 0.25 & 0.25 & 0.25 \\
0.16 & 0.25 & 0.11 & 0.11 & 0.11 \\
0.20 & 0.33 & 0.25 & 0.20 & 0.20 \\
0.09 & 0.16 & 0.09 & 0.09 & 0.09
\end{array}\right]
$$

D. Evaluation results of college students' innovative ability based on the second mathematics classroom

The student's final assessment score vector is:

$$
B=A \circ R=(0.46,0.23,0.155,0.155)
$$

$$
\begin{gathered}
=\left(\begin{array}{ccccc}
0.25 & 0.4 & 0.5 & 0.25 & 0.25 \\
0.2 & 0.18 & 0.18 & 0.1 & 0.1 \\
0.17 & 0.17 & 0.2 & 0.17 & 0.17 \\
0.15 & 0.3 & 0.3 & 0.21 & 0.15
\end{array}\right) \\
=(0.155,0.17,0.2,0.2,0.155)
\end{gathered}
$$

According to the principle of maximum subordination, the student's final innovation ability evaluation result is medium.

Therefore, it can be concluded that the more students participate in the activities of the second class of mathematics, the better the evaluation results of the innovative ability of students, indicating that the activities of the second class of mathematics have a positive role in promoting the cultivation of college students' innovative ability.

\section{CONCLUSION}

With the effective development of the second classroom activities of mathematics and the construction of the evaluation system of students' innovative ability and learning, enthusiasm is significantly improved. The innovation ability is obviously enhanced. The second classroom of mathematics and the first classroom are harmoniously developed, which effectively promotes the teachers and the professional growth of the team. In the future, it is necessary to give full play to the online learning platform and continuously expand the field of mathematics second classroom activities.

\section{REFERENCES}

[1] Chen Chuan. Application Research of Virtual Learning Community in Promoting the Innovation Ability of Normal Students[M]. China Excellent Master's Thesis Full-text Database.

[2] Ou Haiyan. Construction and Innovation of the Second Class Comprehensive Quality Education Platform in Colleges and UniversitiesJ]. Journal of Jilin Province College of Education, 2014(9): 29-31.

[3] Limin MaQian Zhang.On the Innovation Ability of College Students under the Multi-Factor Control[M].Computer Science and Electronic Technology International Society.ICEMEET 2016.

[4] He Shi. Cultivation of Students' Innovative Quality in Applied Undergraduate Colleges[J]. Journal of Fujian Institute of Engineering, 2007(10), pp.446-449.

[5] Han Zhonggeng. Mathematical Modeling Method and Its Application (Second Edition)[M]. Beijing: Higher Education Press, 2009

[6] Wang Tao, Wang Yanping. Fuzzy Mathematics and Its Applications (Second Edition)[M].Shenyang: Northeastern University Press, 2009.

[7] Li Chenxi. Research on the Relationship between the Second Classroom of University and the Cultivation of College Students' Innovative Quality[J]. Statistics and management, 2017(5), pp.172-173. 